\title{
The association of eating behaviors with blood pressure levels in college students: a cross-sectional study
}

\author{
Yan Chen ${ }^{1,2}$, Zhengmei Fang ${ }^{2}$, Lijun Zhu ${ }^{2}$, Lianping He ${ }^{3}$, Huaqing Liu ${ }^{1,4}$, Chengchao Zhou ${ }^{1,5}$ \\ ${ }^{1}$ Centre for Health Management and Policy Research, School of Public Health, Cheeloo College of Medicine, Shandong University, Jinan, China; \\ ${ }^{2}$ School of Public Health, Wannan Medical College, Wuhu, China; ${ }^{3}$ School of Medicine, Taizhou University, Taizhou, China; ${ }^{4}$ School of Public Health, \\ Bengbu Medical College, Bengbu, China; ${ }^{5}$ NHC Key Laboratory of Health Economics and Policy Research, Shandong University, Jinan, China \\ Contributions: (I) Conception and design: Y Chen, C Zhou; (II) Administrative support: Y Chen, H Liu; (III) Provision of study materials or patients: \\ Y Chen; (IV) Collection and assembly of data: Z Fang, L Zhu, L He; (V) Data analysis and interpretation: Y Chen, Z Fang; (VI) Manuscript writing: \\ Y Chen; (VII) Final approval of manuscript: All authors. \\ Correspondence to: Chengchao Zhou. Centre for Health Management and Policy Research, School of Public Health, Cheeloo College of Medicine, \\ Shandong University, No. 44 Wenhua West Road, Jinan 250012, China. Email: zhouchengchao@sdu.edu.cn.
}

\begin{abstract}
Backgrounds: The present study aimed to investigate the relationship between eating habits and blood pressure levels in college students in order to provide more insights into the prevention and control of hypertension.

Methods: A self-administered questionnaire was distributed to first-year college students. The demographic characteristics, eating behaviors, smoking and drinking status, and physical activity of 3,324 eligible respondents were analyzed. Multivariate logistics regression model was used to analyze the association of eating behaviors with blood pressure levels.

Results: The study participants had a mean (SD) age of 18.51 (1.00) years. The mean systolic blood pressure (SBP) and diastolic blood pressure (DBP) levels were 114.08 and $70.92 \mathrm{mmHg}$, respectively. The overall prevalence of hypertension was $7.2 \%$; and the prevalence among males and females was $12.9 \%$ and $3.2 \%$, respectively. Multivariate logistic regression results confirmed that students' taste preference, desserts, and late-night snacks were associated with hypertension. Students who ate spicy food had a lower risk of high blood pressure $(\mathrm{OR}=0.642, \mathrm{P}=0.028)$; as was having dessert 3-6 times a week $(\mathrm{OR}=0.702, \mathrm{P}=0.037)$, while those who ate late-night snacks on 6-7 days of the week had a higher risk for hypertension $(\mathrm{OR}=2.093$, $\mathrm{P}=0.013)$.
\end{abstract}

Conclusions: More targeted interventions should be taken to improve students' eating habits and control their blood pressure.

Keywords: Eating behaviors; eating habits; blood pressure; hypertension

Submitted Dec 01, 2020. Accepted for publication Jan 05, 2021.

doi: 10.21037/atm-20-8031

View this article at: http://dx.doi.org/10.21037/atm-20-8031

\section{Introduction}

Hypertension is considered to be a risk factor for complications such as stroke, coronary heart disease, and other cardiovascular events (1). By 2025, an estimated 1.56 billion people will be affected by hypertension globally (2). The Global Burden of Disease has reported that high systolic blood pressure (SBP) is expected to remain as the single biggest contributor to the global disease burden, with this burden expanding as the population ages (3). An unhealthy lifestyle and genetic factors are considered to be the main contributors to elevated blood pressure. Adopting a reasonable lifestyle is the most economical and effective way to prevent and control hypertension. Indeed, guidelines from the United States (4), China (5), and Europe (6) include recommendations on diet and lifestyle, advocating 
reduced dietary salt intake and increased intake of fresh fruit and vegetables. However, even the relationship between salt intake and cardiovascular disease is controversial (7).

In adolescents, short-term elevated blood pressure heightens the risk of developing hypertension as an adult. Tirosh et al. found that the incidence of hypertension among adults who had a baseline blood pressure of 130 $139 / 85-89 \mathrm{mmHg}$ as an adolescent was $14.53 \%$ for men and $4.94 \%$ for women, which represented a 3 -fold increase in the incidence rate compared to that of peers (8). Nonpharmacological interventions, including the adoption of healthy dietary habits, are considered important for the prevention of hypertension in adolescents. Recently, a number of studies have been conducted to evaluate the relationship between eating habits and blood pressure (9-11). The CARDIA study reported that eating breakfast daily was associated with a hazard ratios (HR) for hypertension of 0.84 (95\% CI, 0.72-0.99) in young adults (12). Meanwhile, a longitudinal study of 8153 middle-aged adults found that while night-time eating habits were not associated with a higher risk of hypertension, the risk of obesity was increased (13). However, studies on eating habits and blood pressure levels in Chinese adolescents and young adults are lacking.

Therefore, this study aimed to assess the relationship between eating habits and blood pressure levels in college students in order to provide more insights into the prevention and control of hypertension. We present the following article in accordance with the STROBE reporting checklist (available at http://dx.doi.org/10.21037/atm-208031).

\section{Methods}

\section{Participants and study design}

The present study used a cross-sectional study design and was conducted between September and November, 2018. A total of 3,450 first-year students at a medical college were invited to participate; the response rate was $99.42 \%$ $(3,430$ students). A preliminary investigation was conducted before the survey and the questionnaire was modified and improved. The formal investigation was carried out by investigators with unified training. Before the investigation began, all respondents signed the informed consent form; at the same time, the investigators gave the corresponding guidance. The questionnaires were collected on the spot after completion, and checked in time. The questionnaire included questions on the students' demographic characteristics, eating behaviors, smoking and drinking status, and physical activity. For the analysis, blood pressure measurements also needed to be taken. Finally, 106 subjects for whom blood pressure measurements or eating variables were missing were excluded, and the remaining 3,324 eligible subjects were included in the final analysis.

The study procedures were approved by the Scientific Research Institutional Review Board of Yijishan Hospital of Wannan Medical College (No. 2018-32), and written informed consent was obtained from all the participants. All procedures performed in this study involving human participants were in accordance with the Declaration of Helsinki (as revised in 2013).

\section{Eating habits questionnaire design}

The questions included in the eating habits questionnaire are shown below, along with the possible answers in brackets.

1. How would you describe your taste preference? (Salty/bland/sweet/spicy)

2. Do you regularly eat 3 meals a day? (Yes/no)

3. How many days have you skipped breakfast in the past week? ( $\leq 2$ days/3-5 days/ $6-7$ days)

4. How many types of vegetables do you eat every day? ( $\leq 2$ types $/ 3-5$ types $>5$ types)

5. How would you describe your daily diet? (Mostly meat/mostly vegetables/balanced between meat and vegetables)

6. How many times have you eaten fresh fruit in the past week? ( $\leq 2$ times $/ 3-6$ times/once a day/ $\geq 2$ times a day)

7. How many times have you had carbonated drinks (e.g., lemonade or cola) in the past week? ( $\leq 2$ times/3-6 times/once a day/ $\geq 2$ times a day)

8. How many times have you had snacks (e.g., sweets, chocolate, or pastry) in the past week? ( $\leq 2$ times/3-6 times/once a day/ $\geq 2$ times a day)

9. How many times have you eaten food from a roadside stand in the past week? ( $\leq 2$ times/3-6 times/once a day/ $>2$ times a day)

10. How many times have you had instant noodles in the past week? ( $\leq 2$ times $/ 3-6$ times/once a day/ $\geq 2$ times a day)

11. How many days have you eaten a meal in a Western fast food restaurant in the past week? ( $\leq 2$ days/3-5 days/ $6-7$ days)

12. How many days have you had at least 1 glass of milk or 
Table 1 The characteristics and health behaviors of students $(n=3,324)$

\begin{tabular}{lccc}
\hline Item & Mean \pm SD or N (\%) & $\mathrm{N}(\%)$ & $\mathrm{N}(\%)$ \\
\hline Mean age (years) & $18.51 \pm 1.00$ & & \\
Mean SBP (mmHg) & $114.08 \pm 13.68$ & & Female, 62 (3.2) \\
Mean DBP (mmHg) & $70.92 \pm 10.56$ & Male, 177 (12.9) & Unspecified, 10 (0.3) \\
Hypertension, $\mathrm{n}(\%)$ & Overall, $239(7.2)$ & No, 2,386 (71.8) & Unspecified, 6 (0.2) \\
Regular exercise, $\mathrm{n}(\%)$ & Yes, $928(27.9)$ & No, 3,278 (98.6) & Unspecified, 10 (0.3) \\
Current smoking habit, $n(\%)$ & Yes, $40(1.2)$ & No, 3,288 (98.9) &
\end{tabular}

$\mathrm{SD}$, standard deviation; SBP, systolic blood pressure; DBP, diastolic blood pressure.

soy milk in the past week? ( $\leq 2$ days/3-5 days/6-7 days)

13. How many days have you had late-night snacks in the past week? ( $\leq 2$ days/3-5 days/ $6-7$ days)

14. How many days have you eaten fried food in the past week? ( $\leq 2$ days $/ 3-5$ days/6-7 days)

\section{Physical examinations}

Blood pressure was measured after the subjects had rested well for 5 minutes. The blood pressure of each subject was measured twice (with a 1-minute interval) in a seated position, using an automated electronic sphygmomanometer (Omron U30, Japan). Hypertension in individuals aged $\geq 16$ years old was defined as $\mathrm{SBP} \geq 140 \mathrm{mmHg}$ and/or diastolic blood pressure (DBP) $\geq 90 \mathrm{mmHg}$ (14). Physical activity was defined as exercise causing heavy sweating or a large increase in breathing or heart rate that lasted at least 30 minutes per day for $\geq 3$ times a week (15). Current smoking status and current alcohol intake were defined by "yes" or "no".

\section{Statistical analysis}

Continuous data were presented as means \pm standard deviation (SD) and compared using the $t$-test or oneway analysis of variance (ANVOA). Categorical variables were described as percentages and compared using the Chi-square test. The associations between eating habits and hypertension were assessed by performing logistic regression analyses to estimate odds ratios (OR) and their 95\% confidence intervals (CI). Multiple logistic regression models were used to further correct for covariates, including age, sex, physical activity, current smoking status, and current alcohol intake.
Statistical analyses were performed using SPSS version 26.0 (SPSS, Inc., Chicago, IL, USA). Results with a 2-tailed $\mathrm{P}$ value of 0.05 were considered statistically significant.

\section{Results}

\section{Characteristics of the subjects}

The 3,324 eligible subjects (including 1,372 males) enrolled in this study had a mean (SD) age of 18.51 (1.00) years old. The mean SBP and DBP levels were 114.08 and $70.92 \mathrm{mmHg}$, respectively. The overall prevalence of hypertension was $7.2 \%$; among males and females the prevalence was $12.9 \%$ and $3.2 \%$, respectively. The majority of students $(86.6 \%)$ ate 3 meals regularly every day, and $73.5 \%$ ate breakfast $\geq 6$ times a week. Of the students, $27.9 \%$ exercised regularly. Few students had a habit of smoking (1.2\%) or drinking (0.8\%). See Table 1 .

\section{The difference in blood pressure levels among students with different eating babits}

Students who preferred to eat spicy food or sweet food had significantly lower blood pressure than students who preferred to eat bland or salty food, while those who preferred salty food had higher blood pressure than those who liked bland food $(\mathrm{P}<0.001$ in SBP; $\mathrm{P}=0.009$ in $\mathrm{DBP})$. The students whose diets consisted mainly of vegetables had lower blood pressure than those diets consisted mainly meat $(\mathrm{P}=0.007$ in $\mathrm{SBP} ; \mathrm{P}=0.039$ in $\mathrm{DBP})$, but no difference was found in blood pressure in terms of the how many kinds of vegetables. Students who ate late-night snacks and drank carbonated drinks had significantly higher blood pressure than those who did not (all $\mathrm{P}<0.05)$. Students with 
a habit of eating fruit and eating food from roadside stands had lower blood pressure levels (all $\mathrm{P}<0.05$ ). The blood pressure of students who frequently ate dessert showed a slight $\mathrm{U}$-shaped trend, and the lowest point was in the 1/ day group $(\mathrm{P}<0.001$ in SBP; $\mathrm{P}=0.002$ in $\mathrm{DBP})$. The detailed results are shown in Table 2.

\section{The association of eating habits with hypertension}

Univariate logistic regression found that taste preference, meal composition, fruit intake, carbonated drinks, dessert, eating food from roadside stands, and late-night snacks were associated with hypertension (Table 3). The results of multivariate logistic regression confirmed the association between students taste preferences, dessert, and late-night snacks. Eating spicy food was significantly associated with hypertension $[\mathrm{OR}=0.642$, 95\% CI: $0.433-0.954$ (vs. bland food); $\mathrm{P}=0.028]$. Having dessert 3-6 times a week was associated with hypertension [OR $=0.702,95 \%$ CI: $0.504-$ 0.978 ( $v s$ s $\leq 2$ times); $\mathrm{P}=0.037$ ], as was eating late-night snacks 6-7 days per week [OR $=2.093,95 \%$ CI: $1.165-3.760$ (vs. $\leq 2$ days); $\mathrm{P}=0.013]$ (Table 4).

\section{Discussion}

Through physical examination and questionnaire survey of the 3,324 students, we found that the prevalence of hypertension in males $(12.9 \%)$ was much higher than that in females $(3.2 \%)$. It may be due to gender differences, the female's menstrual periods and estrogen have a certain protective effect on their blood pressure. Previous epidemiological studies have indicated that various dietary factors may affect the regulation of blood pressure. This study further showed that some eating habits can influence blood pressure.

In this study, we confirmed a clear relationship between salt intake and blood pressure levels. Compared with those students who preferred a bland diet, the mean SBP of students who preferred salty food was $1.7 \mathrm{mmHg}$ higher. There is sufficient evidence that high sodium consumption is a risk factor for hypertension both in children and adults, and reducing sodium intake has been advocated globally (16-18). A pooled analysis of 4 large prospective studies indicated that increased sodium intake in individuals with hypertension resulted in a larger increase in SBP (2.08 $\mathrm{mmHg}$ change per $\mathrm{g}$ sodium increase) than that seen in normotensive individuals (1.22 $\mathrm{mmHg}$ change per $\mathrm{g}$ ), while low sodium intake ( $<3 \mathrm{~g} /$ day) increased the risk of cardiovascular events and death, regardless of whether an individual was hypertensive or not (19). The results suggested that for people with normal blood pressure, strict control of salt intake may not have cardiovascular benefits. Although our study once again confirmed that salt consumption was associated with increased blood pressure, we did not carry out a quantitative assessment of sodium intake, which meant that the relationship between sodium intake levels and hypertension could not be analyzed further.

Interestingly, we also found that students with a preference for sweet food had lower blood pressure levels than those with bland diets. This finding was consistent with an observation made by another Chinese study that people with a 'sweet tooth' dietary pattern were less likely to have high blood pressure (20). However, inconsistent results have also been reported. In Payab et al.'s study of 14,880 Iranian children and adolescents (21), no association was observed between sweet consumption and hypertension. Further, Majane et al. demonstrated that a diet high in sugar and saturated fat resulted in hypertension in spontaneously hypertensive rats (22). Moreover, in this study, a U-shaped trend was found between dessert frequency and blood pressure levels. These results suggest that the consumption of suitable sweets has no adverse effect on blood pressure. The explanation for this phenomenon may be that sweets can make people feel good (23), and an inverse association between negative emotions and blood pressure has been reported (24).

Late-night snacks have been reported to be associated with cardiovascular disease (25), as well as diabetes (26). A previous study reported that for individuals who ate supper before going to bed, the risk of acute onset hypertension was $27 \%$ higher than that of individuals who did not (27). We found a positive association between the frequency of latenight snacking and blood pressure, as well as an increased risk of hypertension among students who regularly ate late at night. The mechanism underlying this may be related to the increase in other risk factors for hypertension, such as the increase in total cholesterol and low-density lipoprotein (LDL) cholesterol, as well as the reduction of fat oxidation, caused by snacking at night. This indicates that eating at night can change fat metabolism, thus increasing the risk of obesity $(28,29)$.

Regarding the consumption of carbonated drinks, a type of sugar-sweetened beverage, significant differences were found between consumption frequency and hypertension. According to Chen et al., a reduction in sugar-sweetened 
Table 2 Differences in blood pressure levels of students with different eating habits (mean \pm SD)

\begin{tabular}{|c|c|c|c|c|c|c|c|c|}
\hline Question & Answer & $\mathrm{N}(\%)$ & $\mathrm{SBP}(\mathrm{mmHg})$ & $F / t$ & $P$ value & $\mathrm{DBP}(\mathrm{mmHg})$ & $\mathrm{F} / \mathrm{t}$ & $P$ value \\
\hline \multirow{3}{*}{ Taste } & Salty & 405 (12.2) & $116.19 \pm 14.3$ & & & $72.13 \pm 11.36$ & & \\
\hline & Sweet & $214(6.4)$ & $112.68 \pm 13.47$ & & & $71.04 \pm 10.27$ & & \\
\hline & Spicy & 787 (23.7) & $112.35 \pm 12.81$ & 8.795 & $<0.001$ & $69.99 \pm 10.1$ & 3.896 & 0.009 \\
\hline Regular diet & No & $445(13.4)$ & $114.02 \pm 13.65$ & 0.424 & 0.515 & $70.77 \pm 10.51$ & 1.881 & 0.060 \\
\hline \multirow[t]{3}{*}{ Skipping breakfast } & $\leq 2$ days & $2,444(73.5)$ & $113.9 \pm 13.75$ & & & $70.88 \pm 10.4$ & & \\
\hline & $3-5$ days & $690(20.8)$ & $114.37 \pm 13.53$ & & & $71.13 \pm 10.61$ & & \\
\hline & 6-7 days & $190(5.7)$ & $115.41 \pm 13.43$ & 1.258 & 0.284 & $70.7 \pm 12.31$ & 0.187 & 0.830 \\
\hline Vegetable intake & $>5$ types & $133(4.0)$ & $114.8 \pm 14.58$ & 1.135 & 0.321 & $69.96 \pm 10.77$ & 0.593 & 0.553 \\
\hline \multirow[t]{3}{*}{ Meal composition } & Mainly meat & $487(14.7)$ & $114.9 \pm 13.44$ & & & $71.17 \pm 9.93$ & & \\
\hline & Mainly vegetables & $753(22.7)$ & $112.75 \pm 13.29$ & & & $70.06 \pm 10.51$ & & \\
\hline & Balanced & $2,084(62.7)$ & $114.37 \pm 13.86$ & 4.901 & 0.007 & $71.18 \pm 10.7$ & 3.236 & 0.039 \\
\hline \multirow[t]{4}{*}{ Fruit intake } & $\leq 2$ times & 904 (27.2) & $116.18 \pm 13.99$ & & & $71.78 \pm 11.11$ & & \\
\hline & 3-6 times & $1,561(47.0)$ & $113.25 \pm 13.39$ & & & $70.42 \pm 10.37$ & & \\
\hline & 1/day & $653(19.6)$ & $113.93 \pm 13.63$ & & & $71.11 \pm 10.18$ & & \\
\hline & $\geq 2 /$ day & $206(6.2)$ & $111.68 \pm 13.66$ & 11.220 & $<0.001$ & $70.36 \pm 10.48$ & 3.433 & 0.016 \\
\hline \multirow{3}{*}{ Dessert } & 3-6 times & $1,047(31.5)$ & $112.82 \pm 13.09$ & & & $70.51 \pm 10.25$ & & \\
\hline & 1/day & $215(6.5)$ & $110.62 \pm 12.43$ & & & $68.69 \pm 10.26$ & & \\
\hline & $\geq 2 /$ day & $103(3.1)$ & $114.03 \pm 13.04$ & 11.564 & $<0.001$ & $70.73 \pm 10.07$ & 5.092 & 0.002 \\
\hline \multirow[t]{4}{*}{ Roadside stands* } & $\leq 2$ times & $2,810(84.5)$ & $114.49 \pm 13.77$ & & & $71.09 \pm 10.58$ & & \\
\hline & 3-6 times & $485(14.6)$ & $112.03 \pm 13.05$ & & & $69.97 \pm 10.42$ & & \\
\hline & 1/day & $27(0.8)$ & $109.07 \pm 11.87$ & & & $70.52 \pm 10.04$ & & \\
\hline & $\geq 2 /$ day & $2(0.1)$ & & 8.678 & $<0.001$ & & 2.348 & 0.096 \\
\hline \multirow[t]{4}{*}{ Instant noodles* } & $\leq 2$ times & $2,888(86.9)$ & $114.01 \pm 13.67$ & & & $71.03 \pm 10.49$ & & \\
\hline & 3-6 times & $396(11.9)$ & $114.85 \pm 13.97$ & & & $70.21 \pm 11.11$ & & \\
\hline & 1/day & $33(1.0)$ & $111.78 \pm 11.44$ & & & $70.28 \pm 9.98$ & & \\
\hline & $\geq 2 /$ day & $7(0.2)$ & & 1.229 & 0.293 & & 1.130 & 0.323 \\
\hline
\end{tabular}

Table 2 (continued) 
Table 2 (continued)

\begin{tabular}{|c|c|c|c|c|c|c|c|c|}
\hline Question & Answer & N (\%) & $\mathrm{SBP}(\mathrm{mmHg})$ & $\mathrm{F}$ & $P$ value & $\mathrm{DBP}(\mathrm{mmHg})$ & $\mathrm{F}$ & $P$ value \\
\hline \multirow{2}{*}{ Western fast food } & $3-5$ days & $88(2.6)$ & $113.82 \pm 13.31$ & & & $70.22 \pm 10.97$ & & \\
\hline & 6-7 days & $22(0.7)$ & $116.23 \pm 14.89$ & 0.287 & 0.751 & $73.41 \pm 12.14$ & 0.808 & 0.446 \\
\hline \multirow[t]{2}{*}{ Milk or soy milk } & $\leq 2$ days & 1,117 (33.6) & $114.21 \pm 13.63$ & & & $71.27 \pm 10.97$ & & \\
\hline & $6-7$ days & $826(24.8)$ & $114 \pm 13.46$ & 0.073 & 0.929 & $70.88 \pm 10.35$ & 1.044 & 0.352 \\
\hline \multirow[t]{3}{*}{ Late-night snacks } & $\leq 2$ days & $2,543(76.5)$ & $113.77 \pm 13.21$ & & & $70.82 \pm 10.36$ & & \\
\hline & $3-5$ days & 649 (19.5) & $114.75 \pm 14.69$ & & & $71.28 \pm 11.25$ & & \\
\hline & 6-7 days & $132(4.0)$ & $116.82 \pm 16.89$ & 4.076 & 0.017 & $71.14 \pm 10.84$ & 0.510 & 0.600 \\
\hline Fried food & 6-7 days & $83(2.5)$ & $112.59 \pm 12.61$ & 1.950 & 0.142 & $70.27 \pm 11.37$ & 0.311 & 0.732 \\
\hline
\end{tabular}

*, the $\geq 2$ /day group is too small and has been combined with the 1/day group. P, probability; SD, standard deviation; SBP, systolic blood pressure; DBP, diastolic blood pressure.

Table 3 Univariate logistic regression results of the association between eating habits and hypertension

\begin{tabular}{|c|c|c|c|c|c|}
\hline Question & Answer & $\mathrm{n}$ & OR & $95 \% \mathrm{Cl}$ & $P$ value \\
\hline \multirow{3}{*}{ Taste } & Salty & 405 & 1.555 & $1.096-2.207$ & 0.013 \\
\hline & Sweet & 214 & 0.85 & $0.482-1.499$ & 0.573 \\
\hline & Spicy & 787 & 0.531 & $0.361-0.782$ & 0.001 \\
\hline Regular diet & No & 445 & & & \\
\hline \multirow[t]{3}{*}{ Skipping breakfast } & $\leq 2$ days & 2,444 & Reference & & \\
\hline & $3-5$ days & 690 & 1.409 & $0.846-2.346$ & 0.188 \\
\hline & $6-7$ days & 190 & 1.097 & $0.794-1.515$ & 0.574 \\
\hline Vegetable intake & $>5$ types & 133 & 1.268 & $0.678-2.369$ & 0.458 \\
\hline \multirow[t]{3}{*}{ Meal composition } & Balanced & 487 & Reference & - & - \\
\hline & Mainly meat & 753 & 0.691 & $0.458-1.044$ & 0.079 \\
\hline & Mainly vegetables & 2,084 & 0.669 & $0.472-0.949$ & 0.024 \\
\hline \multirow[t]{2}{*}{ Fruit intake } & $\leq 2$ times & 904 & Reference & & \\
\hline & $3-6$ times & 1,561 & 0.624 & $0.460-0.847$ & 0.002 \\
\hline
\end{tabular}

Table 3 (continued) 
Table 3 (continued)

\begin{tabular}{|c|c|c|c|c|c|}
\hline Question & Answer & $\mathrm{n}$ & OR & $95 \% \mathrm{Cl}$ & $P$ value \\
\hline & $\geq 2 /$ day & 206 & 0.867 & $0.503-1.493$ & 0.606 \\
\hline \multirow[t]{3}{*}{ Carbonated drinks* } & $\leq 2$ times & 2,892 & Reference & & \\
\hline & 3-6 times & 373 & 1.854 & $1.306-2.631$ & 0.001 \\
\hline & $\geq 2 /$ day & 7 & & & \\
\hline \multirow[t]{3}{*}{ Dessert } & $\leq 2$ times & 1,959 & Reference & & \\
\hline & 3-6 times & 1,047 & 0.580 & $0.424-0.793$ & 0.001 \\
\hline & 1/day & 215 & 0.352 & $0.163-0.759$ & 0.008 \\
\hline \multirow{3}{*}{ Roadside stands* } & 3-6 times & 485 & 0.574 & $0.366-0.899$ & 0.015 \\
\hline & 1/day & 27 & 0.894 & $0.211-3.785$ & 0.879 \\
\hline & $\geq 2 /$ day & 2 & & & \\
\hline \multirow[t]{4}{*}{ Instant noodles* } & $\leq 2$ times & 2,888 & Reference & & \\
\hline & 3-6 times & 396 & 1.100 & $0.743-1.630$ & 0.635 \\
\hline & 1/day & 33 & 0.332 & $0.045-2.429$ & 0.278 \\
\hline & $\geq 2 /$ day & 7 & & & \\
\hline Western fast food & $\leq 2$ days & 3,214 & Reference & & \\
\hline \multirow[t]{3}{*}{ Late-night snacks } & $\leq 2$ days & 2,543 & Reference & & \\
\hline & $3-5$ days & 649 & 1.344 & $0.980-1.842$ & 0.067 \\
\hline & $6-7$ days & 132 & 1.962 & $1.137-3.387$ & 0.015 \\
\hline \multirow[t]{3}{*}{ Fried food } & $\leq 2$ days & 2,556 & Reference & & \\
\hline & $3-5$ days & 685 & 0.755 & $0.531-1.073$ & 0.117 \\
\hline & $6-7$ days & 83 & 0.780 & $0.312-1.951$ & 0.596 \\
\hline
\end{tabular}

${ }^{*}$, the $\geq 2$ /day group is too small and has been combined with the 1/day group. P, probability; OR, odds ratio; Cl, confidence interval.

beverage consumption of 1 time per day in adults was associated with a $1.8-\mathrm{mmHg}$ reduction in SBP and $1.1-\mathrm{mmHg}$ reduction in DBP (30). However, in children and adolescents, another study found no significant association between sugar-sweetened beverages and hypertension (21). Research on the relationship between carbonated drinks and hypertension is sparse. However, with the increase in the consumption of carbonated drinks 
Table 4 Multivariate logistic regression results of the association between eating habits and hypertension

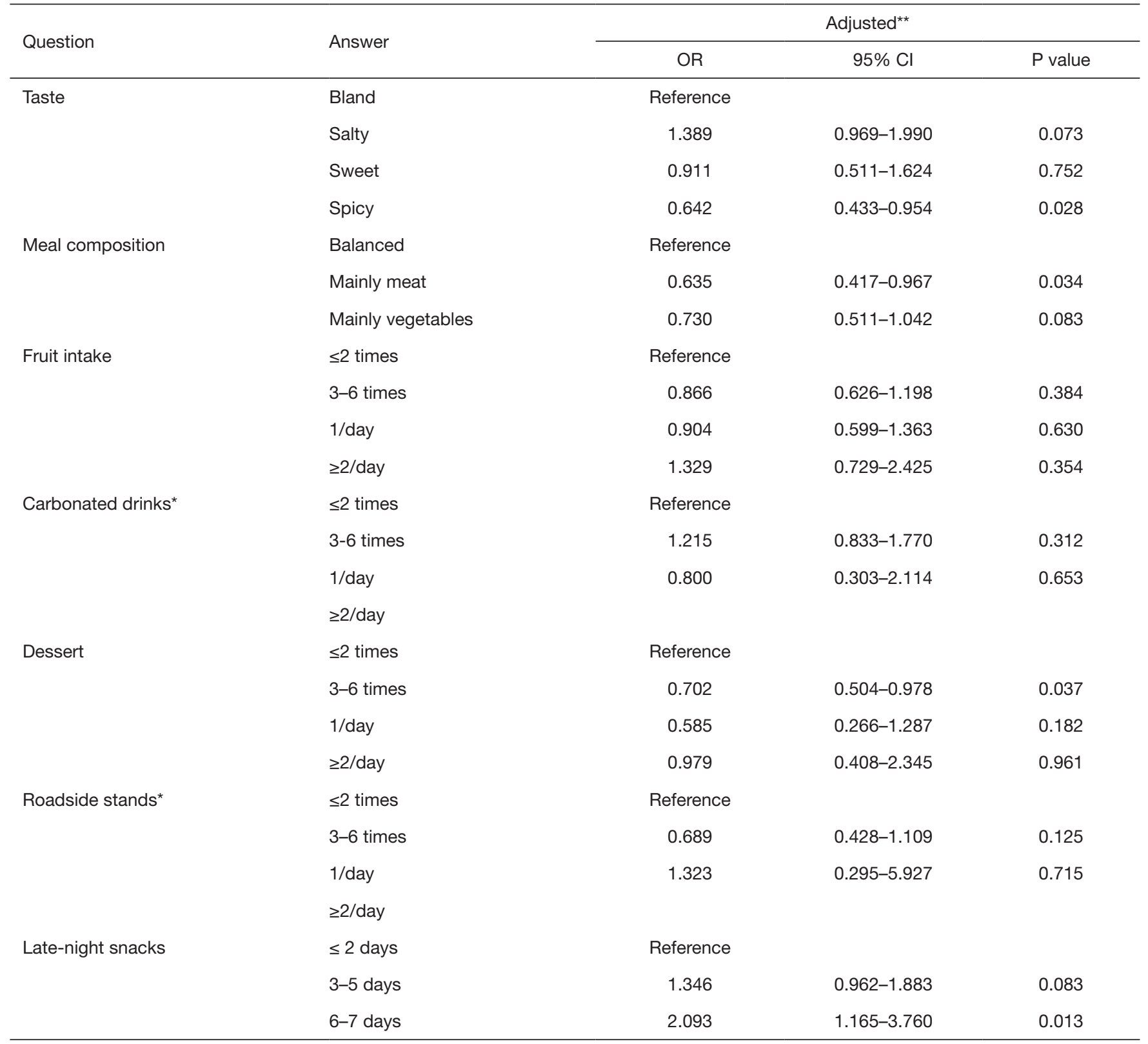

${ }^{*}$, the $\geq 2 /$ day group is too small and has been combined it with the 1/day group; ${ }^{* *}$, adjusted for age, sex, physical activity, current smoking status, and current alcohol intake. P, probability; OR, odds ratio; $\mathrm{Cl}$, confidence Interval.

among college students, research on this relationship is worthy of attention.

We also found that students who preferred a spicy diet had the lowest blood pressure levels among the 4 tastepreference groups, along with a lower risk of hypertension. Similar results were obtained in previous studies. He et al. found that a higher frequency of spicy food consumption was significantly associated with lower SBP and DBP, and lower risk of hypertension in women (31). According to a random-order, double-blind observational and interventional study, subjects with a strong preference for spicy food had a lower salt intake and lower blood pressure than subjects who had other taste preferences (32). However, in a recent study, a preference for spicy food 
was found to be negatively correlated with diabetes risk, but not with hypertension (33). These results suggested that the application of spicy flavoring may be an actionable behavioral intervention for reducing high salt intake and blood pressure.

In our study, we observed a significant association between blood pressure and fruit intake; however, this association was no longer significant after adjusted the covariates in multivariate regression analysis.

This study has some limitations. Firstly, we replaced the specific food consumption with a food frequency questionnaire because of the all of the most students dine in the school cafeteria, the precise amount of food consumed was unknown, and the relationship between food consumption and blood pressure was not explored, that may affect the results of this study. Secondly, this study has a cross-sectional design; therefore, the causal relationship between eating habits and blood pressure could not be determined. Another limitation is that the canteen in which the students in this study eat mostly serves food typical of southern China, thus making it impossible extrapolate our results to other populations. Nevertheless, we believe that these limitations do not invalidate the results obtained.

In conclusion, frequent late-night snacking and desserts, and a preference for spicy food were associated with hypertension in college students. Moreover, a significant association existed between salt intake, carbonated drinks, fruits, and blood pressure levels. These results suggest that more effective interventions or changes in the eating habits of students are necessary.

\section{Acknowledgments}

This research was supported by Anhui Provincial Natural Science Foundation (No. 1808085QH283) and the Natural Science Research Project of Anhui Educational Committee (No.2019A0302).

\section{Footnote}

Reporting Checklist: The authors have completed the STROBE reporting checklist. Available at http://dx.doi. org/10.21037/atm-20-8031

Data Sharing Statement: Available at http://dx.doi. org/10.21037/atm-20-8031

Conflicts of Interest: All authors have completed the ICMJE uniform disclosure form (available at http://dx.doi. org/10.21037/atm-20-8031). The authors have no conflicts of interest to declare.

Ethical Statement: The authors are accountable for all aspects of the work in ensuring that questions related to the accuracy or integrity of any part of the work are appropriately investigated and resolved. The study procedures were approved by the Scientific Research Institutional Review Board of Yijishan Hospital of Wannan Medical College (No. 2018-32), and written informed consent was obtained from all the participants. All procedures performed in this study involving human participants were in accordance with the Declaration of Helsinki (as revised in 2013).

Open Access Statement: This is an Open Access article distributed in accordance with the Creative Commons Attribution-NonCommercial-NoDerivs 4.0 International License (CC BY-NC-ND 4.0), which permits the noncommercial replication and distribution of the article with the strict proviso that no changes or edits are made and the original work is properly cited (including links to both the formal publication through the relevant DOI and the license). See: https://creativecommons.org/licenses/by-nc-nd/4.0/.

\section{References}

1. Poulter NR, Prabhakaran D, Caulfield M. Hypertension. Lancet 2015;386:801-12.

2. Kearney PM, Whelton M, Reynolds K, et al. Global burden of hypertension: analysis of worldwide data. Lancet 2005;365:217-23.

3. Disease GBD, Injury I, Prevalence C. Global, regional, and national incidence, prevalence, and years lived with disability for 354 diseases and injuries for 195 countries and territories, 1990-2017: a systematic analysis for the Global Burden of Disease Study 2017. Lancet 2018;392:1789-858.

4. Whelton PK, Carey RM, Aronow WS, et al. 2017 ACC/ AHA/AAPA/ABC/ACPM/AGS/APhA/ASH/ASPC/ NMA/PCNA Guideline for the Prevention, Detection, Evaluation, and Management of High Blood Pressure in Adults: A Report of the American College of Cardiology/ American Heart Association Task Force on Clinical Practice Guidelines. Hypertension 2018;71:e13-e115.

5. Joint Committee for Guideline R. 2018 Chinese Guidelines for Prevention and Treatment of 
Hypertension-A report of the Revision Committee of Chinese Guidelines for Prevention and Treatment of Hypertension. J Geriatr Cardiol 2019;16:182-241.

6. Williams B, Mancia G, Spiering W, et al. 2018 ESC/ESH Guidelines for the management of arterial hypertension: The Task Force for the management of arterial hypertension of the European Society of Cardiology and the European Society of Hypertension: The Task Force for the management of arterial hypertension of the European Society of Cardiology and the European Society of Hypertension. J Hypertens 2018;36:1953-2041.

7. O'Donnell MJ, Mente A, Smyth A, et al. Salt intake and cardiovascular disease: why are the data inconsistent? Eur Heart J 2013;34:1034-40.

8. Tirosh A, Afek A, Rudich A, et al. Progression of normotensive adolescents to hypertensive adults: a study of 26,980 teenagers. Hypertension 2010;56:203-9.

9. Thawornchaisit P, de Looze F, Reid CM, et al. Health risk factors and the incidence of hypertension: 4-year prospective findings from a national cohort of 60569 Thai Open University students. BMJ Open 2013;3:e002826.

10. Lee SA, Cai H, Yang G, et al. Dietary patterns and blood pressure among middle-aged and elderly Chinese men in Shanghai. Br J Nutr 2010;104:265-75.

11. Wang D, He Y, Li Y, et al. Dietary patterns and hypertension among Chinese adults: a nationally representative cross-sectional study. BMC Public Health 2011;11:925.

12. Odegaard AO, Jacobs DR Jr, Steffen LM, et al. Breakfast frequency and development of metabolic risk. Diabetes Care 2013;36:3100-6.

13. Yoshida J, Eguchi E, Nagaoka K, et al. Association of night eating habits with metabolic syndrome and its components: a longitudinal study. BMC Public Health 2018;18:1366.

14. Lurbe E, Agabiti-Rosei E, Cruickshank JK, et al. 2016 European Society of Hypertension guidelines for the management of high blood pressure in children and adolescents. J Hypertens 2016;34:1887-920.

15. Kelishadi R, Majdzadeh R, Motlagh ME, et al. Development and Evaluation of a Questionnaire for Assessment of Determinants of Weight Disorders among Children and Adolescents: The Caspian-IV Study. Int J Prev Med 2012;3:699-705.

16. Overwyk KJ, Zhao L, Zhang Z, et al. Trends in Blood Pressure and Usual Dietary Sodium Intake Among Children and Adolescents, National Health and Nutrition Examination Survey 2003 to 2016. Hypertension 2019;74:260-6.
17. Watanabe S, Konta T, Ichikawa K, et al. The association between urinary sodium excretion and blood pressure in a community-based population: the Yamagata (Takahata) study. Clin Exp Nephrol 2019;23:380-6.

18. Graudal N, Hubeck-Graudal T, Jurgens G, et al. Doseresponse relation between dietary sodium and blood pressure: a meta-regression analysis of 133 randomized controlled trials. Am J Clin Nutr 2019;109:1273-8.

19. Mente A, O'Donnell M, Rangarajan S, et al. Associations of urinary sodium excretion with cardiovascular events in individuals with and without hypertension: a pooled analysis of data from four studies. Lancet 2016;388:465-75.

20. Qin Y, Melse-Boonstra A, Pan X, et al. Association of dietary pattern and body weight with blood pressure in Jiangsu Province, China. BMC Public Health 2014;14:948.

21. Payab M, Kelishadi R, Qorbani M, et al. Association of junk food consumption with high blood pressure and obesity in Iranian children and adolescents: the CASPIANIV Study. J Pediatr (Rio J) 2015;91:196-205.

22. Majane OH, Vengethasamy L, du Toit EF, et al. Dietaryinduced obesity hastens the progression from concentric cardiac hypertrophy to pump dysfunction in spontaneously hypertensive rats. Hypertension 2009;54:1376-83.

23. Sulmont-Rosse C, Drabek R, Almli VL, et al. A crosscultural perspective on feeling good in the context of foods and beverages. Food Res Int 2019;115:292-301.

24. Dich N, Rod NH, Doan SN. Both High and Low Levels of Negative Emotions Are Associated with Higher Blood Pressure: Evidence from Whitehall II Cohort Study. Int J Behav Med 2020;27:170-8.

25. Cahill LE, Chiuve SE, Mekary RA, et al. Prospective study of breakfast eating and incident coronary heart disease in a cohort of male US health professionals. Circulation 2013;128:337-43.

26. Gouda M, Matsukawa M, Iijima H. Associations between eating habits and glycemic control and obesity in Japanese workers with type 2 diabetes mellitus. Diabetes Metab Syndr Obes 2018;11:647-58.

27. Kakamu T, Hidaka T, Kumagai T, et al. Unhealthy changes in eating habits cause acute onset hypertension in the normotensive community-dwelling elderly-3 years cohort study. Medicine (Baltimore) 2019;98:e15071.

28. Hibi M, Masumoto A, Naito Y, et al. Nighttime snacking reduces whole body fat oxidation and increases LDL cholesterol in healthy young women. Am J Physiol Regul Integr Comp Physiol 2013;304:R94-R101.

29. Palla L, Almoosawi S. Diurnal Patterns of Energy Intake 
Derived via Principal Component Analysis and Their Relationship with Adiposity Measures in Adolescents: Results from the National Diet and Nutrition Survey RP (2008(-)2012). Nutrients 2019;11:422.

30. Chen L, Caballero B, Mitchell DC, et al. Reducing consumption of sugar-sweetened beverages is associated with reduced blood pressure: a prospective study among United States adults. Circulation 2010;121:2398-406.

31. He T, Wang M, Tian Z, et al. Sex-dependent difference in the association between frequency of spicy food

Cite this article as: Chen Y, Fang Z, Zhu L, He L, Liu H, Zhou C. The association of eating behaviors with blood pressure levels in college students: a cross-sectional study. Ann Transl Med 2021;9(2):155. doi: 10.21037/atm-20-8031 consumption and risk of hypertension in Chinese adults. Eur J Nutr 2019;58:2449-61.

32. Li Q, Cui Y, Jin R, et al. Enjoyment of Spicy Flavor Enhances Central Salty-Taste Perception and Reduces Salt Intake and Blood Pressure. Hypertension 2017;70:1291-9.

33. Zhao Z, Li M, Li C, et al. Dietary preferences and diabetic risk in China: A large-scale nationwide Internet data-based study. J Diabetes 2020;12:270-8.

(English Language Editor: J. Reynolds) 